\title{
Initial attachment of Borrelia burgdorferi spirochetes to Vero cells
}

\author{
Schwarzova $\mathrm{K}^{1}$, Ciznar I², Svihrova $\mathrm{V}^{3}$, Hudeckova $\mathrm{H}^{3}$ \\ Institute of Microbiology, Faculty of Medicine Comenius University and University Hospital, \\ Bratislava, Slovakia. katarina.schwarzova@fmed.uniba.sk
}

\begin{abstract}
BACKGROUND: Adhesion is the initial process in the establishment of any infection and can contribute to bacterial pathogenesis. Without the ability to adhere to host cell surface, there is no invasion, dissemination, or persistence and host colonization by many bacterial pathogens, including $B$. burgdorferi. During the infection, $B$. burgdorferi cells interact with cells of various origins. We are having limited information and knowledge regarding the borrelial invasion, intracellular existence and the host cell damage and the pathological effects to the host. We have investigated by electron microscope the adherence of motile Borrelia burgdorferi s.l. to Vero cells derived from the kidney of an African green monkey by electronmicroscopy. These cells have been shown as an interesting model for study of the toxic potential of many bacterial pathogens. METHODS: Adherence of the long-term in vitro passaged Borrelia burgdorferi sensu lato strains to a 24-hour monolayer of primate kidney epithelial Vero cells was studied using transmission electronmicroscopy. The reaction was read after incubation at 1-hour intervals.

RESULTS: A vertical contact between borreliae and Vero cells was confirmed already after one hour of in vitro incubation. A cytotoxic effect of borreliae could be observed when the time of incubation was extended to 4 hour. The extent of attachment varied between the two borrelia strains tested.

CONCLUSION: The optimal time for spirochetal adhesion in our model was $1 \mathrm{~h}$ postinoculation. Our results suggest that borrelia attaches to the tested cells by length and by the tip. The data showed that the extent of attachment varied between the two borrelia strains tested (Tab. 1, Fig. 4, Ref. 21). Text in PDF www.elis.sk. KEY WORDS: Borrelia; pathogenesis of LB, attachment of invasive spirochete, epithelial Vero cells.
\end{abstract}

\section{Introduction}

Borrelia burgdorferi spirochete is the causative agent of Lyme borreliosis (LB). LB is occuring in around 85000 cases in Europe and in around 20000 cases in USA yearly, thus becoming the tick-born infectious disease number one $(7,12,15)$. The infection presents with signs of multi-system disorders in patients body. The symptoms are highly variable and overlapping with symptoms of other diseases causing organ and systemic disorders. For this reason the disease was named ,, great imitator of many diseases“. It is a disease presenting from subacute to chronic form, from local to generalized form. The etiological agent of LB, the spirochetal invasive gram-negative bacterium Borrelia burgdorferi s.l. is represented mainly by Borrelia garinii ( $\mathrm{Bg})$, Borrelia afzelii $(\mathrm{Ba})$ and Borrelia burgdorferi sensu stricto ( $B b$ s.s). The main vector for these spirochetes is the tick, genus Ixodes. The habitat in the nature

${ }^{1}$ Institute of Microbiology, Faculty of Medicine Comenius University and University Hospital, Bratislava, Slovakia, ${ }^{2}$ Faculty of Medicine, Ostrava University, Ostrava, Czech Republic, and ${ }^{3}$ Department of Public Health, Jessenius Faculty of Medicine, Comenius University, Martin, Slovakia

Address for correspondence: $\mathrm{K}$. Schwarzová, $\mathrm{PhD}$, Institute of Microbiology, Faculty of Medicine Comenius University and University Hospital, Spitalska 24, SK-813 72 Bratislava, Slovakia.

Phone: +421.2 .9011624$ for the tick Ixodes ricinus has covered in the past the regions of central and southern Slovakia with altitude up to 400 meters about sea level (a.s.1.). Currently, due to the climatic changes, changes in land use and cover, and human induced environmental changes the ticks have spread into higher altitude, up to $1000 \mathrm{~m}$ a.s.l. and more into northern latitudes. Similar trends have been observed in all of Europe. Also the disease seasonal incidence has been observed to be shifting towards spring and autumn (7).

Pathogenesis of LB as well as factors and mechanisms of pathogenicity of the causative agent of this debilitating disease are up to now not elucidated completly. B. burgdorferi does not replicate to high numbers in the bloodstream, so it is difficult to study the pathobiology of the disease in clinical material (6). Also the isolation of the pathogen from body fluids can be problematic, because the numbers of spirochetes are low and bactericidal factors may suppress their growth. The scientific information, and the knowledge of structural and functional roles of these factors and mechanisms are the base for development of more effective diagnostic, therapeutic and preventive tools important for the control of the disease $(2,6$, $16,8,21)$. Borrelias transmitted by ticks during the blood feeding on the host are interacting with many factors of the host body. The entry of Borrelia into the host determinates the process of the disease with interaction of the pathogen and macrophages. It was found that the spirochetes residing in the salivary glands of the tick are far more infective than those residing in the midgut $(4,5,10,11)$. 
Tab. 1. Borrelia burgdorferi s.l. strains used in the study.

\begin{tabular}{lccc}
\hline Borrelia species & Strain & Isolation & Source \\
\hline Bb. s.s & B31 & Ixodes dammini & USA \\
B. $g$. & K48 & Ixodes ricinus & Slovakia \\
\hline
\end{tabular}

At present there is also a gap in the understanding of infection dynamic proceses such as spirochetal invasion and possible host cell damage, intravascular transport of borrelia, mechanisms of borrelia escape from the vascular network and possible components involved in organotropism.

Presence of a variety of substances on the pathogen cell surface substantiates chemical and physical properties of the cell such as surface charge, hydrophobicity/ hydrophilicity, antigenicity/immunogenicity. These properties have a profound impact on the activity of bacterial cell to adhere to host cell receptors, to interact with host cells and to colonise the different loci in the host.

\section{Materials and methods}

Two strains of B. burgdorferi used in the study (Tab. 1) were isolated from lxodes ticks and cultivated under identical standard growth conditions in the modified BSK - H medium (Sigma, USA). Each cultivation bottle containing $100 \mathrm{~mL}$ BSK-H medium was inoculated with $5 \mathrm{~mL}$ of an exponential-phase spirochetal culture (concentration of $10^{6}$ cells per $\mathrm{mL}$ ) as described previously (18, 19). Spirochetes were incubated for $6-7$ days at $34{ }^{\circ} \mathrm{C}$ to a cell concentration of $10^{8} / \mathrm{mL}$ and examined weekly under dark field microscopy (magnification $200 \times$ ).

\section{Cultivation of Vero cells with spirochetal cultures}

Attachment of B. burgdorferi to Vero cells was studied as described previously $(1,3,13)$. Briefly, $2 \times 10^{8}$ spirochetes were coincubated with Vero cells in modified BSK medium at $37^{\circ} \mathrm{C}$. The cultures were taken after 1, 2 and 3 hours (h). The media were decanted and the flasks were washed twice with BSK medium to remove non-adherent spirochetes. The cells were harvested for electron microscopy up to $1 \mathrm{~h}$ postinfection.

\section{Transmission electron microscopy}

The spirochete - Vero cell monolayers were fixed with $4 \%$ formaldehyde and $1 \%$ glutaraldehyde in phosphate buffer, $\mathrm{pH} 7.2$, for $1 \mathrm{~h}$, gently scraped off the plastic flasks and negatively stained with $3 \%$ phosphotungstic acid. The adherence was examined by electron microscopy as already described (18).

\section{Results}

Interaction of Vero cells with B. burgdorferi was monitored. The suspension in the exponential phase of growth in E-MEM medium at a concentration of $10^{8}$ cells per $\mathrm{mL}$ was applied on a 24 hour monolayer of Vero cells. The reaction was read after incubation at $37^{\circ} \mathrm{C}$ at one hour intervals (Fig. 1). Most of the spirochetes were detected either free in the cytoplasm or tightly bound to the host membrane. During incubation up to 1 hour adherence with characteristic vertical contact between B. garinii and Vero cells could

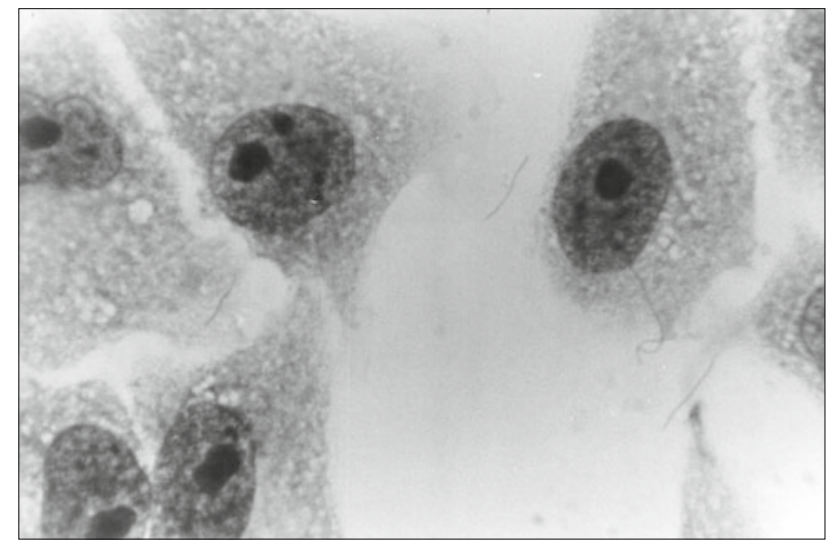

Fig. 1. Attachment of borreliae to Vero cells. The reaction was read after incubation at $37^{\circ} \mathrm{C}$ at 1-h intervals. Typical spiral morphology of borreliae is seen in the electron microscope (EM); negatively stained with $3 \%$ phosphotungstic acid; $\times \mathbf{4 0 0 0}$.

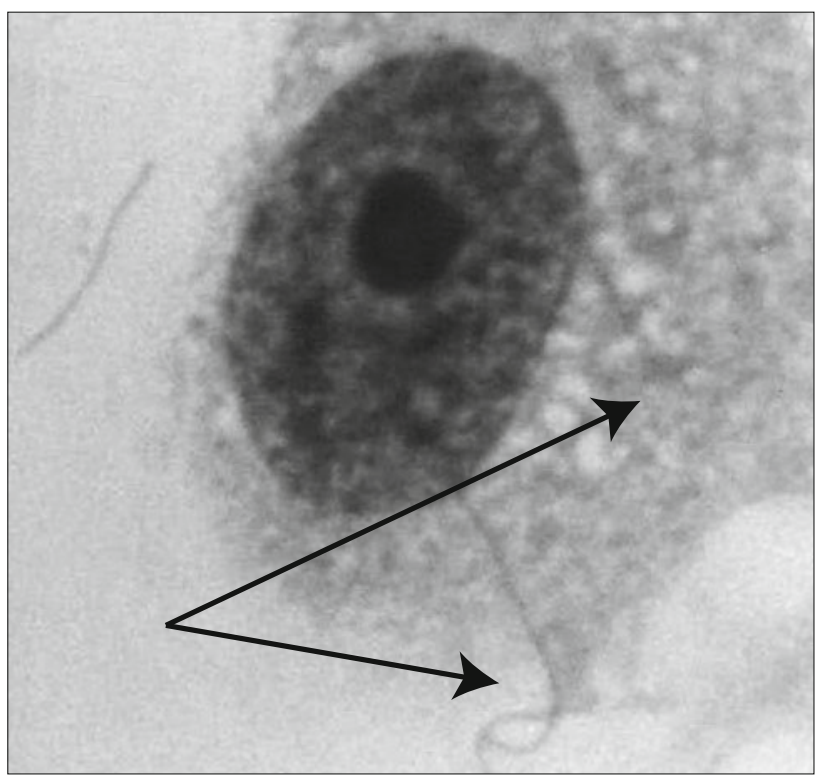

Fig. 2. A vertical contact between B. garinii and Vero cells could be seen (arrow).

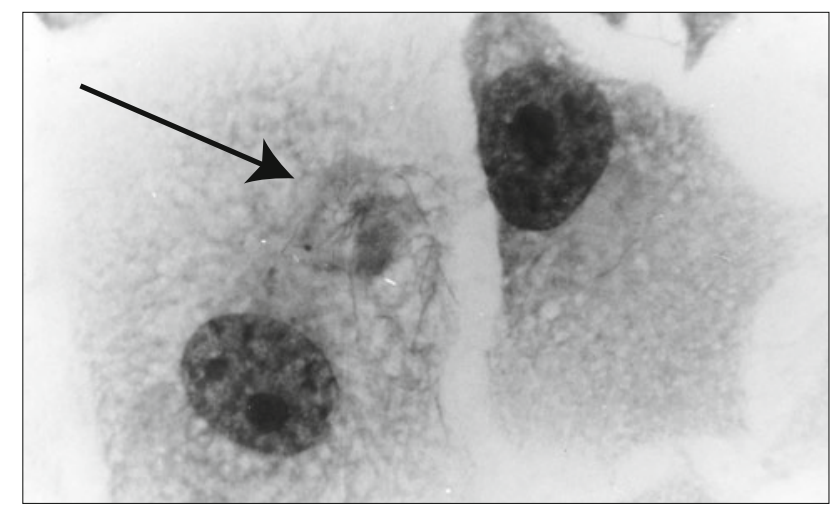

Fig. 3. Attachment of B. burgdorferi s.s. to Vero cells. A cytotoxic effect of borreliae was observed after $2 \mathrm{~h}$ (arrow). EM; negatively stained with $3 \%$ phosphotungstic acid; $\times \mathbf{4 0 0 0}$. 
be seen (Fig. 2). A cytotoxic effect of borreliae could be observed when the time of incubation was extended to 2 hours (Fig. 3).

The results indicate that the spirochetes adhered to mammalian cells mainly by the apical pole and less frequently by the lateral wall. In Vero cells penetration is accomplished especially by cytoplasmic membrane destruction, the spirochetes appearing free in the cytoplasm, but also by phagocytosis. Growth of spirochetes cocultured with five of six lines did not change.

\section{Discussion}

Lyme borreliosis is the most common vector-born disease. However, in spite of the 35 years of research since the first description it has remained a disease with many unresolved issues in the area of diagnosis, therapy and prevention. Particularly the factors and mechanisms of patogenicity of etiological agent $\mathrm{Bb}$ as well as pathogenesis of the disease deserve more research. This situation stands on the controversy about persistent infection caused by the spirochetal agent as well as chronic symptoms in patients diagnosed with LB both under treatment or without treatment in the initial phase of the infection.

Borrelia burgdorferi s.l. the causative agent of LB is an invasive gramnegative bacterium. However, which of the cell surface substances or metabolic products are involved in the invasivity is not yet clear. Whether substances of the invasive proteins similar to other gramnegative bacteria are involved in this process is not known. Neither the possibility that metabolic products with enzymatic activity or modulating activity are involved in this process is excluded. The relevant answer to this questions can be obtained only when based on data and information from experiments utilising the modern laboratory methods applied for the study of the borrelia interaction with structures of the host macroorganism at the molecular and cellular level.

The optimal time point for observation of spirochetal adhesion in our model was $1 \mathrm{~h}$ postinoculation, similar to others (5, 11 ), while the optimal adherence to human endothelial cells occurred after 4 hours of incubation (13). Using scanning electron microscopy, Kurtti et al. observed B. burgdorferi attached by one or both ends to cultured tick cells in cocultivation experiments (11). Our results suggest that attachment occurs both by apical and laminar mode. The data showed that the extent of attachment varied between the two borrelia strains tested. While by B. garinii the cell apical contact with Vero cells has been observed, the cell destruction by $B$. burgdorferi s.s. has been detected. Further examination is needed to determine whether this finding is related to the B. burgdorferi potential to cause damage in mammalian kidney.

B. burgdorferi produces a number of substances that allow it to colonize and persist in its natural mammalian and tick hosts $(2,4,5,6$, $9,20)$. How the spirochete manages to induce the changes necessary to survive in these settings is the subject of intensive investigation.

\section{Conclusion}

Mechanisms involved in the internalization of B. burgdorferi into host cells attachment are at interest in understanding more

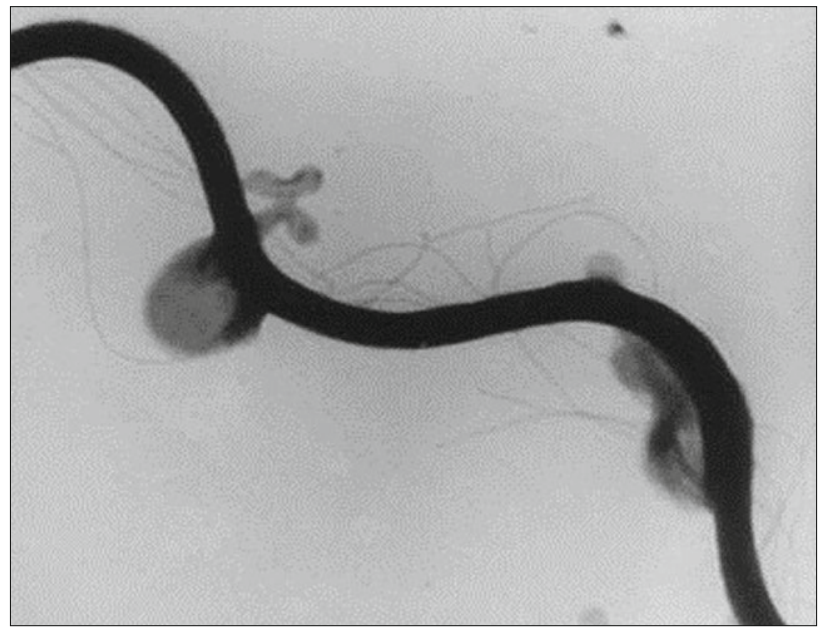

Fig. 4. Spirochetal granules and cyst-like structures found in longtermed in vitro cultivated strains.

about borrelia adherence and invasion into eukaryotic cells. We do not have enough data and information that would help us to understand the pathogenesis of LB at the various levels similarly as in the case of other gramnegative bacteria. This is related also to the reactions at the level of interstitial space of host structures and pathogen. We need more scientific data about the surface stuctures of $B b$ that are invollved in invasive activity, structures involved in the adhesion, tropism, exoproducts and biofilm production suporting substances and mechanisms.

Besides the aspects of the LB pathogenesis as mentioned above, the presence of the cysts and granules (Fig. 4) in persistent LB remains unclear (14). Whether chronic borreliosis is the consequence of the action of persisting spirochetal cells present in the form of biofilm, or L-forms without cell envelop is not clearly defined, however in both cases therapy is needed. Though the options of the therapy for these forms are limited, the eradication of the clinical symptoms deserves an agresive multi-antibiotic therapy similar as in the case of AIDS or TB $(7,8,17,21)$.

\section{References}

1. Bartkova G, Ciznar I. Adherence pattern of non-pilated Aeromonas hydrophila strains to tissue culture. Microbios 1994; 77: 44-55.

2. Berende A, Oosting M, Kullberg BJ, Netea MG, Joosten LA. Activation of innate host defence mechanism by Borrelia. Eur Cytokine Netw 2010; 21 (1): 7-18.

3. Boldiš V, Jasna Štrus J, Kocianová E, Tušek-Žnidarič M, Štefanidesová K, Schwarzová K, Kúdelová M, Sekeyová Z, Špitalská E. Life cycle of Rickettsia slovaca inL929cell line studied by quantitative real-time PCR and transmission electron microscopy. FEMS Microbiol Lett 2009; 293: 102-106.

4. Caine JA, Coburn J. A short-term Borrelia burgdorferi infection model identifies tissue tropisms and bloodstream survival conferred by adhesion proteins. Infect Immun 2015; 83: 3184 -3194.

5. Caine JA, Coburn J. Multifunctional and redundant roles of Borrelia burgdorferi outer surface proteins in tissue adhesion, colonization, and complement evasion. Front Immunol 2016; 7: 442. 
6. Gilmore DR Jr. Immunoseclusion and chronic infection by Borrelia burgdorferi, Chpt. 2. In: Embers ME (Ed). The pathogenic spirochetes: strategies for evasion of host immunity and persistence. Springer science+business media, New York 2012. Doi: 10.1007/978-1-46145404-5_2.

7. Heyman P, Cochez C, Hofhuis A, van der Giessen J, Sprong H, Porter SR, Losson B, Saegerman C, Donoso-Mantke O, Niedrig M, Papa A. A clear and present danger: tick-borne diseases in Europe. Expert Rev Anti Infect Ther 2010; 8 (1): 33-50.

8. Klempner MS, Linden THu, Evans J, Schmid CH, Johnson GM, Trevino RP, Norton D, Levy L, Wall D, McCall J, Kosinski M, Weinstein A. Two controlled trials of antibiotic treatment in patients with persistent symptoms and a history of Lyme disease. N Engl J Med 2001; 345: 85-92.

9. Kraiczy P. Hide and Seek: How Lyme disease spirochetes overcome complement attack. Front Immunol 2016; 26 (7): 385.

10. Kung F, Anguita J, Pal U. Borrelia burgdorferi and tick proteins supporting pathogen persistence in the vector. Future Microbiol 2013; 8: $41-56$.

11. Kurtti TJ, Munderloh UG, Ahlstrand GG, Johnson RC. Borrelia burgdorferi in tick cell culture: growth and cellular adherence. J Med Entomol 1988; 25: 256-261.

12. Lindgren E, Jaenson, TGT. Lyme borreliosis in Europe: influences of climate and climate change, epidemiology, ecology and adaptation measures. 157-188, 2006. In: Menne B, Ebi KL (Eds). Climate Change and Adaptation Strategies for Human Health. Springer, Darmstadt \& WHO, Geneva.
13. Ma Y, Sturrock A,Weis JJ. Intracellular localization of Borrelia burgdorferi within human endothelial cells. Infect Immun 1991; 59 (2): 671-6784.

14. Miklossy J, Kasas S, Zurn AD, McCall S, Yu S, McGeer PL. Persisting atypical and cystic forms of Borrelia burgdorferi and local inflammation in Lyme neuroborreliosis. J Neuroinflammat 2008; 5: 40.

15. Svihrova V, Hudeckova H, Jesenak M, Schwarzova K, Kostanova Z, Ciznar I. Lyme borreliosis-analysis of the trends in Slovakia, 19992008. Folia Microbiol 2011; 56 (3): 270-275.

16. Petnicki-Ocwieja T, Kern A. Mechanisms of Borrelia burgdorferi internalization and intracellular innate immune signaling. Front Cell Infect Microbiol 2014; 4 (175): 1-7.

17. Shapiro ED. Repeat or persistent Lyme disease: persistence, recrudescence or reinfection with Borrelia Burgdorferi? F1000Prime Rep 2015; $7-11$.

18. Schwarzova K, Ciznar I. Combined infection of Ixodes ricinus with three Borrelia burdorferi sensu lato genotypes. Folia Microbiol 2004; 49 (3): $297-300$.

19. Schwarzova K, Ciznar I. Immunochemical analysis of lipopolysaccharide-like component extracted from Borrelia burgdorferi sensu lato. Folia Microbiol 2004; 49 (5): 625-629.

20. Stone BL, Brissette CA. Host immune evasion by Lyme and relapsing fever borreliae: findings to lead future studies for Borrelia miyamotoi. Front Immunol. 2017; 8:12.

21. Stricker RB, Johnson L. Lyme disease: the next decade. Infect Drug Resist 2011; 4: 1-9. 